SHS Web of Conferences 2, 00020 (2012)

DOI: $10.1051 /$ shsconf $/ 20120200020$

(C) Owned by the authors, published by EDP Sciences, 2012

\title{
Correlation between urinary incontinence and localization of brain lesion and severity of neurological lesion caused by a stroke
}

\author{
I. Mihejeva and A. Vetra
}

Rīga Stradinsš University, Latvia

\begin{abstract}
Urinary incontinence is one of the medical problems, which may develop as a result of a stroke, and, according to several authors, its occurrence frequency may reach up to $80 \%$. Clinical symptoms of urinary incontinence are considered to be one of the symptoms, which, along with the severity of the stroke and the level of functional limitations, allows to develop reliable predictions and to make targeted use of resources. Aim of the study, materials and methods. The aim of the study is to explore whether post-stroke urinary incontinence correlates with localization of lesion and clinical symptoms. The study includes 180 patients after a stroke, who have received treatment at Riga Eastern Clinic University Hospital Stroke Unit. All had a comprehensive clinical and functional assessment and cerebral computed tomography (CT). The examination took place at the hospital a few days after the stroke had occurred. Results. There are 180 participants to the study. Symptoms of urinary incontinence were reported for $70.6 \%$ of study participants. In $64 \%$ of cases new incontinence problems had developed, while in $6.5 \%$ of cases the previous symptoms of urinary incontinence (prior to the stroke) had worsened. The most common types of urinary incontinence in the acute period were urge and mixed incontinence (functional and urge incontinence). Patients with low Barthel Index showed higher frequency of urinary incontinence. A comparison of patient groups with and without symptoms of urinary incontinence showed that patients older than 75 years showed more symptoms of urinary incontinence $(\mathrm{p}=0.013)$, and the same can be said about patients with low indicators of Barthel $(\mathrm{p}=0.001)$ and patients with cognitive disorders $(\mathrm{p}=0.001)$. Severity of paresis, aphasia and sensory disorders show a reliable correlation with the type of urinary incontinence.

Conclusion. Symptoms of post-stroke urinary incontinence are linked both to a person's age, and functional and cognitive disorders. Urinary incontinence develops more frequently among patients with anterior circulation of the brain and subcortical brain lesion. There is a reliable correlation between severity of neurological lesion and urinary incontinence.
\end{abstract}

Key words: stroke, rehabilitation, urinary incontinence

Urinary incontinence is a serious health disorder that develops after a stroke and occurs within the first days or weeks after affection in between $37 \%$ and $79 \%$ of cases (Van Kuijk, Van der Linde, Van Limbeek, 2001).

Urinary incontinence is not seen as a specific early symptom of the stroke with characteristic brain lesion localization, however several authors view it as an indicator of potential occurrence of death, disability and re-hospitalization. The most common mechanism of post-stroke urinary incontinence is an increase in activity of bladder wall muscle or detrusor (m.detrusor), yet a decrease in activity of detrusor may be observed and urodynamic testing may show indicators below the norm.

Lesion of various brain structures, movement and speech or language disorders, characteristic to post-stroke patients, may result in a loss of bladder signal and a loss of or limitedness of toilet skills. Several studies show that post-stroke urinary incontinence cases may be divided into two separate clinical categories: "classical urge urinary incontinence" and "urinary incontinence of persons with perception disorders" (Pettersen, Wyller, 2006). Post-stroke patients with urinary incontinence show lower ability to focus in comparison to patients without urinary incontinence. Improvement of the ability to focus is an important task in the process of rehabilitation. Training of attention may stimulate a

This is an Open Access article distributed under the terms of the Creative Commons Attribution License 2.0, which permits unrestricted use, distribution, and reproduction in any medium, provided the original work is properly cited. 


\section{SHS Web of Conferences}

renewal of bladder control for patients who recognize their own urinary incontinence (Pettersen, Saxby, Wyller, 2007). Although information on urinary retention or urgent and frequent need to urinate is widely available, little is known of its original causes and their role in the prediction of recovery results. If bladder control is lost as a result of nerve impulse pathway damage, in most cases not only will the perception be bad, but there will also be poor understanding and perception of the surroundings (Pettersen, Stien, Wyller, 2007; Turhan, Atalay, Atabek, 2006). The factor of nerve growth level, necessary for the growth and regeneration of the nerve, correlates with the severity of neurological lesion of patients with circulatory problems in the brain, and not with symptoms of urinary incontinence and urodynamic indicators (Liu et al., 2009). Lesion of white matter is an important factor in all cases of urinary incontinence, because there is a general disorder in the matters, which are linked to the ability to perceive and to recognize bodily signals. Time should be devoted to reduction of these disorders during the process of rehabilitation (Olsen-Vertland, 2003; Pettersen et al., 2008).

There is an array of factors, which may cause development of urinary incontinence after cerebral infarction (stroke), for instance, the patient is older than 65 years, there is a heightened irritability of detrusor sphincter, which is clinically manifested as an urgent need to urinate or urinary incontinence (Abrams et al., 1998). Other authors have specified such factors of urinary incontinence as micturitions in the damage control mechanism, resulting in a hyper-reflexive bladder, a hypotonic bladder and a "brain shock" for patients, who take anticholinergic medication, post-stroke structural problems in the tract and mobility, communication and perception disorders caused by a stroke (Ween et al., 1996). To this date there is little evidence-based research on clinical types of post-stroke urinary incontinence. Several studies of urodynamics show that a hyperactive detrusor is the most common dysfunction, however it has been proved that changes may occur in the urodynamic after a stroke (Gelber et al., 1993; Gupta et al., 2009). A decrease in the sensory and recognition skills may add up to such characteristic symptoms of a patient as speech, language and cognitive dysfunction or lack of ability to sense and to recognize one's primary needs. Literature describes three basic types of urinary incontinence, most frequently occurring among post-stroke patients during the rehabilitation period: urge urinary incontinence, functional urinary incontinence and stress incontinence. In case of urge urinary incontinence patients complain about urinary leakage in combination with a feeling of urge, which usually is a result of brain lesion or edema causing disorders of micturition control. Functional urinary incontinence is a disability to contain urine due to functional disorders such as movement and communication deficit, which often is combined with limited access to the environment. In case of stress urinary incontinence patients complain about urinary leakage provoked by coughing or sneezing (Abrams et al., 2002), which often is observed prior to the stroke, especially if the cough is linked to aspiration and swallowing disorders (Olsen-Vertland, 2003). A large proportion of patients with movement and cognitive disorders have a variety of reasons for urinary incontinence and various types of urinary incontinence, which may lessen or disappear, once the functional and general health improves (Turhan, Atalay, Atabek, 2006).

Incidence of urinary incontinence in the acute period after the stroke reaches $40-60 \%$; at the time when patients sign out of the hospital it is $25 \%$ and it may persist up to one year after the stroke (Barret, 2001).

\section{Aim of the study}

The study aims to clarify whether post-stroke urinary incontinence and its clinical types are linked to a localization of brain lesion and severity of neurological lesion, age and concomitant illnesses.

\section{Materials and methods}

There are 180 participants to the study, who are patients after their first stroke -102 men and 78 women, who have received treatment at Riga Eastern Clinic University Hospital Stroke Unit in the time period 


\section{Int. Conf. SOCIETY. HEALTH. WELFARE; Congr. of Rehabilitation Doctors of Latvia}

between 1st of February and 30th of June 2009. All of the patients were examined and a diagnosis was set in accordance with the definition of World Health Organization. A stroke is a local or general disorder of brain functions, which occurs suddenly and is observed for 24 hours or more and may cause death; it may be explained by vascular causes, yet it cannot be linked to any demonstrable cause. Brain tomography (CT) was performed for all the patients within 24 hours after admission.

Urine incontinence was defined as urinary leakage more than once a day and no less than for two days. According to the guidelines of the International Continence Society, urinary incontinence is classified as a stress urinary incontinence, urge urinary incontinence and functional urinary incontinence, as well as bladder emptying problems - urinary retention. Urinary analysis was tested for all patients in the acute period in order to exclude urinary tract infections. Residual urine was determined for the patients; residual urine of more than $150 \mathrm{ml}$ was considered urinary retention.

Paresis, sensory disorders and aphasia were assessed by the National Institute of Health Stroke Scale in order to determine their levels of severity (0-none, 1-slight damage, 2- moderate damage, 3-severe damage).

Participants of the study were asked questions on their functioning prior to the stroke; concomitant illnesses, neurological lesion and functional disorders caused by the stroke were assessed; symptoms of urinary incontinence, disability (Barthel index) and cognitive processes (mini-mental state examination) were assessed. Patients were examined within 10 days after hospitalization.

The obtained data was processed with SPSS (version 17.0), by applying descriptive statistics, including frequency, median indicators and standard deviation for quantitative indicators (age, gender etc.). The nonparametric test (correlation coefficient) was used to assess correlation between urinary incontinence and neurological symptoms.

\section{Results}

The study includes 180 patients (78 women/102 men). The average age of participants is 68.0 years (min $36, \max 92)$. The average age of women is $70.8(\mathrm{SD} \pm 9.94)$, the average age of men is $65.9(\mathrm{SD} \pm 13.1)$. By testing the statistical hypothesis of the average age of men and women by an independent samples $\mathrm{t}$-test, it was found that the average age of participants show statistically reliable differences $(\mathrm{t}=2,740$; $\mathrm{p}=0.007)$. The study includes 149 patients with cerebral infarct [women $68(87.2 \%) /$ men $81(79.4 \%)$ ] and 31 patients with spontaneous intracerebral hemorrhage [women $10(12.8 \%) /$ men 21(20.6\%)]. By testing the statistical hypothesis dividing men and women according to the type of stroke by using the chi-square test, no statistically significant differences were found $\left(\chi^{2}=1,871\right.$; df $\left.=1 ; p=0,171\right)$.

The frequency of urinary incontinence in the acute period was $127(70.6 \%) .16$ patients developed urinary retention in the acute period (over $150 \mathrm{ml}$ residual urine), of which 11 patients had suffered a cerebral infarct and 5 patients had suffered a spontaneous intracerebral hemorrhage. Of the 149 patients with cerebral infarct, 95 developed urinary incontinence, divided into types of urinary incontinence: 30 cases of urge urinary incontinence, 3 cases of stress urinary incontinence, 62 cases of functional urinary incontinence. Of the 31 patient with spontaneous intracerebral hemorrhage, 22 developed urinary incontinence, divided into types of urinary incontinence: 4 cases of urge urinary incontinence, 3 cases of stress urinary incontinence, 15 cases of functional urinary incontinence. By testing the statistical hypothesis of types of urinary incontinence according to the type of stroke with the chi-square test, it was found that there are no statistically significant differences in these divisions $\left(\chi^{2}=6.121\right.$; $\mathrm{df}=6$; $\mathrm{p}=0.410)$. The analysis showed that out of the 78 women included in the study 59 women developed urinary incontinence: 23 cases of urge urinary incontinence, 3 cases of stress urinary incontinence and 33 cases of functional urinary incontinence. Of the 102 men included in the study 68 developed urinary incontinence: 11 cases of urge urinary incontinence, 3 cases of stress urinary incontinence, 54 cases of functional urinary incontinence. Statistical hypothesis of urinary incontinence types according to gender was tested by a chi-square test and revealed no reliable statistical differences $\left(\chi^{2}=8.944\right.$; $\mathrm{df}=6$; $\mathrm{p}=0.177)$. 


\section{SHS Web of Conferences}

No link was found between arterial hypertension $\left(\chi^{2}=2.428 ; \mathrm{df}=6 ; \mathrm{p}=0.876\right)$, diabetes $\left(\chi^{2}=\right.$ 5.381; $\mathrm{df}=6 ; \mathrm{p}=0.496)$, heart rhythm disorders $\left(\chi^{2}=6.088 ; \mathrm{df}=6 ; \mathrm{p}=0.413\right)$, alcohol use $\left(\chi^{2}=\right.$ $9.349 ; \mathrm{df}=6 ; \mathrm{p}=0.155)$ or smoking $\left(\chi^{2}=5.530 ; \mathrm{df}=6 ; \mathrm{p}=0.478\right)$ and between a particular type of urinary incontinence.

By analyzing the localization of lesion in order to explore whether the stroke has occurred in the front or back of the brain circulation circle by an independent samples t-test, it was found that urinary incontinence reliably prevails among patients with front of the brain circulation disorders $(\mathrm{t}=$ $31.278 ; p=0.001)$ with localization of subcortical lesion $(p=0.004)$ as opposed to cortical lesion ( $p=0.143$ ), no reliable differences were found between the localization of lesion in the right and the left cerebral hemisphere $(p=0.487)$.

Depth of paresis was linked to post-stroke urinary incontinence. 49 patients did not develop urinary incontinence, of which in $40(82 \%)$ cases there was no development of paresis, in $5(10 \%)$ cases a slight paresis, in $2(4 \%)$ cases a moderate paresis and in $2(4 \%)$ cases a deep paresis. 28 patients developed urge urinary incontinence: in $19(68 \%)$ cases with no subsequent paresis, in $5(18 \%)$ cases a slight paresis, in 2 $(7 \%)$ cases a moderate paresis, and in $2(7 \%)$ cases a deep paresis. 3 patients developed stress urinary incontinence: in $2(68 \%)$ cases without a paresis and in $1(32 \%)$ case a slight paresis. 63 patients developed functional urinary incontinence: in $36(43 \%)$ cases without a paresis, in $6(10 \%)$ cases a slight paresis, in $18(26 \%)$ cases a moderate paresis and in $17(24 \%)$ a deep paresis. 16 patients developed urinary retention, of which $8(50 \%)$ cases without paresis, in 4 (25\%) of cases a slight paresis, in $3(19 \%)$ moderate paresis and $1(6 \%)$ of cases a deep paresis. Division of patients according to depth of paresis and types of urinary incontinence shows statistical reliability $\left(\chi^{2}=38.725 ; \mathrm{df}=18 ; p=0.003\right)$. There is a statistically significant link between urinary incontinence and depth of paresis $(\mathrm{r}=0.337 ; p=0.001)$.

Severity of aphasia was linked to types of post-stroke urinary incontinence. 49 patients did not develop urinary incontinence, of which 6 (12\%) did not develop aphasia, 2 (4\%) developed a moderate aphasia, $41(84 \%)$ developed severe aphasia. 28 patients developed urge urinary incontinence: $2(7 \%)$ cases of slight language disorders, $5(18 \%)$ cases of moderate language disorders, 21 (75\%) cases of severe language disorders. 3 patients were diagnosed with stress urinary incontinence: 1 (33\%) without language disorders, $2(67 \%)$ patients with slight aphasia. 77 patients were diagnosed with functional urinary incontinence: $39(53 \%)$ patients were diagnosed with slight aphasia, $22(32 \%)$ patients were diagnosed with moderate aphasia, $16(15 \%)$ developed severe aphasia. Division of patients according to severity of language disorders and type of urinary incontinence shows statistically reliable differences $\left(\chi^{2}=70.147 ; \mathrm{df}=12 ; p=0.001\right)$. There is a statistically reliable correlation between urinary incontinence and severity of language disorders $(\mathrm{r}=0.425 ; p=0.001)$.

100 patients developed sensory disorders of varying severity. 77 patients did not develop sensory disorders, 3 patients did not develop urinary incontinence, 2 patients developed urge urinary incontinence, 2 patients developed stress urinary incontinence, 57 patients developed functional urinary incontinence, 14 patients developed urinary retention. Of the 58 patients with sensory disorders of moderate severity 11 patients did not develop urinary incontinence, 22 patients developed urge urinary incontinence, 2 patients developed stress urinary incontinence, 18 patients developed functional urinary incontinence, 2 patients developed urinary retention. Of the 42 patients with severe sensory disorders, 35 did not develop urinary incontinence, 4 patients developed urge urinary incontinence, 3 patients developed functional urinary disorders. Division of patients according to sensory disorder severity and urinary incontinence shows statistically reliable differences $\left(\chi^{2}=146.685 ; \mathrm{df}=12 ; p=0.001\right)$. There is a statistically reliable correlation between type of urinary incontinence and severity of sensory disorders $(\mathrm{r}=0.378 ; p=0.001)$.

The above-mentioned results are reflected in Table 1, which shows the division of number of patients according to the type or urinary incontinence, neurological lesion and concomitant illnesses.

A comparison of patient groups with and without post-stroke urinary incontinence, a reliable difference on the level of age, by dividing patients into two groups (older than 75, younger than 75) $(p=0.013)$, functional skills $(p=0.001)$ and cognitive disorders $(p=0.001)$ (Table 2$)$. 
Int. Conf. SOCIETY. HEALTH. WELFARE; Congr. of Rehabilitation Doctors of Latvia

Table 1.

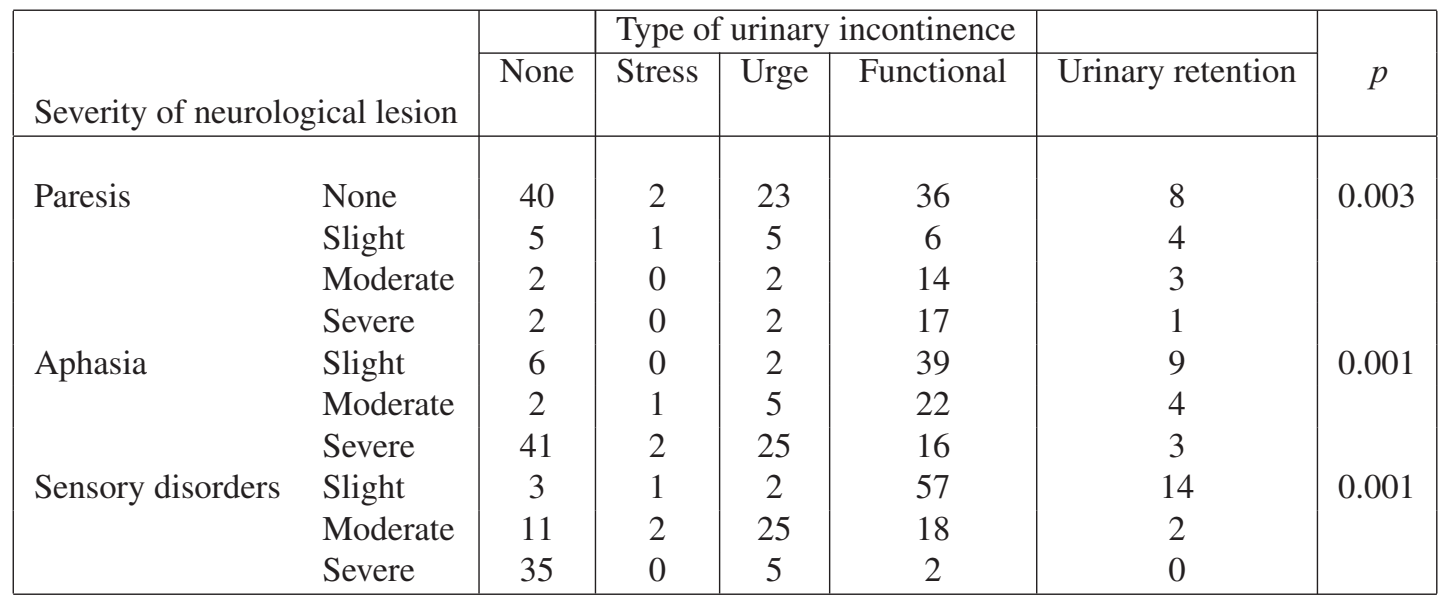

Table 2. Descriptive statistics of the study groups.

\begin{tabular}{|l|c|c|c|c|c|c|c|c|}
\hline & \multicolumn{2}{|c|}{$\begin{array}{c}\text { All patients } \\
(\mathrm{n}=180)\end{array}$} & \multicolumn{2}{c|}{$\begin{array}{c}\text { Patients with } \\
\text { UN (n=130) }\end{array}$} & \multicolumn{2}{c|}{$\begin{array}{c}\text { Patients without } \\
\text { UN }(\mathrm{n}=50)\end{array}$} & \multirow{2}{*}{$t$} & \multirow{2}{*}{$t$} \\
\cline { 2 - 7 } & Average & SD & Average & SD & Average & SD & & \\
\hline & & & & & & & & \\
Age & 69 & \pm 11.2 & 80.0 & \pm 11.7 & 65.6 & \pm 9.1 & $p=0.013$ & $t=2.531$ \\
Barthel Index & 42.1 & \pm 31.9 & 31.6 & \pm 27.1 & 68.3 & \pm 25.9 & $p=0.001$ & $t=7.7038$ \\
MMSE & 16.7 & \pm 8.0 & 15.1 & \pm 8.0 & 21.4 & \pm 5.4 & $p=0.001$ & $t=4.463$ \\
\hline
\end{tabular}

UN, PSUI, post-stroke urinary incontinence; SD, standard deviation.

The age of patients shows a reliable correlation with cognitive disorders $(p=0.001)$; no significant correlation was found between age, urinary incontinence and functional disability, yet post-stroke urinary incontinence more often occurs among patients older than 75 . There is a reliable correlation between functional disability (Barthel Index), cognitive disorders (MMSE) $(p=0.001)$ and post-stroke urinary incontinence $(p=0.001)$.

\section{Discussion}

Routine monitoring of urinary incontinence is not a widespread approach in the treatment of poststroke patients either in hospital or in further rehabilitation environment. This health problem is often considered to be of secondary importance, requiring responsibility from the care staff. Urinary incontinence should be explored not only as a medical problem, but also as a social problem, and a multi-professional team must engage in finding a solution for it. Early prevention of urinary incontinence should allow a timely identification of the risk of medical and social problems. Thommenssen (1999), Patel (2001), Tilling (2001), van Kuijk (2001) and co-authors concluded that urinary incontinence is a negative predictive indicator of functional recovery of post-stroke patients. In 2003 Vanags et al. developed a predictive model of death rate in the first year after the stroke to be used in clinical practice. This model contained eight characteristics. Urinary incontinence was inserted on top of the list with the highest indicator -9 , followed by dysphagia -7 , other indicators being 4 or less. A summary of this data shows that urinary incontinence is considered to be a reliable predictive factor, which shows a negative functional result after the stroke. The results of our study lead to the conclusion that functional 


\section{SHS Web of Conferences}

recovery is worse among patients with functional urinary incontinence, which is linked to movement and cognitive disorders.

\section{Conclusion}

There is a higher frequency of post-stroke urinary incontinence for persons older than 75 with severe functional disability and cognitive disorders. There is no link between gender or type of stroke and post-stroke urinary incontinence in the acute post-stroke period. There is a statistically significant correlation between severity of paresis and urinary incontinence. There is a statistically significant correlation between severity of aphasia and the type of urinary incontinence. There is a statistically significant correlation between sensory disturbance and urinary incontinence. Occurrence of post-stroke urinary incontinence is more common among patients with front of the brain circulation disorders and subcortical brain lesion.

\section{References}

[1] Van Kuijk, A.A., Van der Linde, H., Van Limbeek, J. (2001) Urinary incontinence in stroke patient after admission to a post acute inpatient rehabilitation program. Arch. Phys. Med. Rehabil., 82, p. 1407-1411.

[2] Abrams, P., Blaivas, J.G., Stanton, S.L., Andersen, J.T. (1998) Standartization of terminology of urinary tract function. Neurol Urodyn, 7, p. 403-427.

[3] Ween, J.E., Alexander, M., D’Esposito, M., Roberts, M. (1996) Incontinence after stroke in a rehabilitation setting: outcomes association and predictive factors. Neurology, 47, p. 659-663.

[4] Gelber, D.A., Good, D.C., Laven, L.J., Verhulst, S.J. (1993) Causes of urinery incontinence after acute hemispheric stroke. Stroke, 24, p. 378-382.

[5] Pettersen, R., Stien, R., Wyller, T.B. (2007) Post-stroke urinary incontinence with impaired awareness of the need to void: clinical and urodynamic features. BJU Intern 99, p. 1073-1077/ doi:10.1111/j.1464-410X.2007.06754.X

[6] Abrams, P., Cordozo, L., Fall, M., Griffiths, D., Rosier, P., Ulmsten, U., van Kerrebroeck, P., Viktor, A., Wein, A. (2002) The standartization of terminology of urinary tract function: Report from the standartization subcommittee of International Continence Society. Neurol Urodyn, 21, p. 167-178.

[7] Olsen-Vertland, P. (2003) Urinary Incontinence after a cerebro-vascular accident. Nursing Standards, 17, p. 37-41.

[8] Turhan, N., Atalay, A., Atabek, H.K. (2006) Impact of stroke etiology, lesion location and aging on post-stroke urinary incontinence as a predictor of functional recovery. Intern. Jour. of Rehab. Research, 29(4), p. 335-338.

[9] Barret, J.A. (2001) Bladder and bowel problems after stroke. Reviews in Clinical Gerontology, 12, p. 253-267.

[10] Pettersen, R., Wyller, T.B. (2006) Prognostic significance of micturition disturbances after acute stroke. J. Am. Geriatr. Soc., 54, p. 1878-84.

[11] Pettersen, R., Saxby, B.K., Wyller, T.B. (2007) Post-stroke urinary incontinence: one-year outcome and relationships with measures of attentiveness. J. Am. Geriatr. Soc, 55(10), p. 15711577.

[12] Liu, H.T., Liu, A.B., Chancellor, M.B., Kuo, H.C. (2009) Urinary nerve growth factor level is correlated with the severity of neurological impairment in patients with cerebrovascular accident. BJU Int., 104(8), p. 1158-62. Epub 2009 Mar 30. 
Int. Conf. SOCIETY. HEALTH. WELFARE; Congr. of Rehabilitation Doctors of Latvia

[13] Pettersen, R., Haig, Y., Nakstad, P.H., Wyller, T.B. (2008) Subtypes of urinary incontinence after stroke: relation to size and location of cerebrovascular damage. Age Ageing, 37 (3), p. 324-327. doi: 10.1093/ageing/afm196

[14] Gupta, A., Taly, A.B., Srivastava, A., Thyloth, M. (2009) Urodynamics post-stroke in patients with urinary incontinence: Is there correlation between bladder type and site of lesion? Ann. Indian. Acad. Neurol., 12(2), p. 104-107. 